\title{
In pursuit of a self-conscious science
}

\author{
J. O'Keefe and P.D. Wall
}

FOR the half-century between 1920 and 1970, most neurophysiologists and experimental psychologists were content to leave "consciousness" outside the boundaries of their disciplines. The properties traditionally attributed to consciousness freedom of the will, creativity, selfknowledge - seemed difficult, if not impossible, to capture within the accepted notions of deterministic science. Furthermore there was a strong reaction to the use of consciousness as an explanatory device: two actions were different because one was voluntary; two stimuli differed because one was attended to.

In recent years this radical behaviourist approach has been modified and recent work has thrust the problem of consciousness to the forefront again. One scientist who deserves considerable credit for insisting on a place for consciousness in neurophysiology during this scientific dark night of the soul is the author of the book under review. In 1953, Sir John Eccles published a book entitled The Neurophysiological Basis of Mind (Oxford University Press) which was quite the best summary up to that time of how nerve impulses pass from one cell to another. Having been for many years one of the main proponents of the electrical synapse theory, Eccles accepted the new evidence for the chemical synapse and became one of the architects of our modern understanding of neuronal transmission, for which work he received the Nobel prize in 1964.

In 1953 virtually no aspect of brain research had a direct bearing on the question of consciousness and Professor Eccles's inclusion of a final chapter on this topic was regarded as a mild eccentricity. Consciousness entered the scientific picture as a subtle force operating at the level of the indeterminate synapse. Eccles's preoccupation with the brain-mind problem has increased over the years: the last chapter of the 1953 book has become the first chapter of the present book. The book is divided into three sections. The first section (Lectures 1 and 2) sets out Eccles's current theory of the mind which he has developed in association with the philosopher Sir Karl Popper. The second (Lectures 3-6) describes recent experiments in neurophysiology and psychology which bear on the question of consciousness, and the third (Lectures 7-10) marks a shift to a consideration of
The Human Psyche. The Gifford Lectures, University of Edinburgh 1978-1979. By John C. Eccles. Pp.279. ISBN 3-540-09954-9. (Springer-Verlag: 1980.) DM44, \$26.

the broader issues of the relation between consciousness and social values.

Eccles's theory of consciousness views it as an entity which exists independently of the brain but which interacts strongly with it. He rejects materialist theories which identify consciousness with the activity of a part or all of the brain. The brainconsciousness interaction takes place at the level of the cerebral cortex which unfortunately does not have the appropriate anatomical structure. Whereas consciousness appears to be a unity which maintains its integrity and continuity over time, the cerebral cortex consists of numerous, relatively independent modules each coding for a different aspect of the sensory environment or motor behaviour. Eccles concludes that ". . . the unity of conscious experience is provided by the self-conscious mind and not by the neural machinery of the liaison areas of the cerebral hemisphere", (p.50). How is this accomplished?

the self-conscious mind can scan the activity of each module of the liaison brain or at least those modules tuned in to its present interest . the self-conscious mind has the function of integrating its selections from the immense patterned input it receives from the liaison brain. . . in order to build its experiences from moment-to-moment [p.46].

It would appear that on this formulation the problem of consciousness is inaccessible to neurophysiological analysis and perhaps to any scientific analysis. It is a non-neural entity with its own structure, interests, expectations and creative impulses, attributes which are never discussed but which are constantly invoked to "explain" psychological and physiological findings.

Much of the middle section of the book is an excellent description of recent findings. As might be expected from the author's preoccupation with the cerebral cortex as the part of the brain which liaises with the self-conscious mind, much (and by far the most satisfactory part) of this section deals with effects ascribable to the cortex. Visual illusions show that much of the sensory world is created by the brain from inadequate data; EEG recordings of the brain potentials from the scalp show that cortical activity precedes voluntary movements and accompanies anticipated stimuli. Unfortunately, these fascinating findings are "explained" by hand-waving references to the self-conscious brain. Since the "explanation" is given in terms of a world with normal scientific rules, one may reasonably ask for experiments to investigate this world, but as we approach it retreats as a will'o the wisp.

Subsequent chapters give a cursory but adequate account of the limbic system, the pain system and the reticular activating system of the brainstem. Professor Eccles acknowledges that these may have some bearing on the problem of consciousness but keeps his sights firmly fixed on the cerebral cortex. A surmise in the section on the limbic mechanisms of emotion "that Gary Gilmour, the last criminal to be executed in the United States, may have been suffering from amygdaloid seizures" (p.116-117) warns us of what to expect in the third and final section of the book: the relation between brain, consciousness and social values.

This last section contains a wide ranging set of comments and quotations on topics centred around the twilight area where scientific ideas impinge upon social values. Professor Eccles is particularly severe on scientists who would reduce human action or human values to mechanistic explanations. The sociobiologist E.O. Wilson who seeks to explain altruistic behaviour on the basis of selfish genes and the molecular biologist Jacques Monod who seeks to emphasize the chance elements in human existence come in for special opprobrium. Although some cogent arguments are advanced, much of the discussion takes the form of poetic quotations from suitably authoritative sources: Sherrington, Planck, Heisenberg, Eddington and Einstein. We suggest that most readers will take these last chapters for what they are: the personal prejudices of a great neurobiologist who has strayed outside the bounds of his area of expertise. We hope it won't deter them from giving serious consideration to the earlier chapters.

J. O'Keefe and P.D. Wall are members of the Cerebral Functions Research Group at University College, University of London. 